\title{
Peramalan Tingkat Inflasi Indonesia Menggunakan Neural Network Backpropagation Berbasis Metode Time Series
}

\author{
Amrin \\ Program Studi Manajemen Informatika \\ AMIK Bina Sarana Informatika Jakarta \\ J1. Kramat Raya No.18 Jakarta Pusat, Jakarta, Indonesia \\ amrin.ain@bsi.ac.id
}

\begin{abstract}
In this study will be used back propagation neural network method to predict the monthly inflation rate in Indonesia. In the results of the data analysis is concluded that the performance of back propagation neural network that formed by the training data and validated by testing data generates prediction accuracy rate is very good with a mean square error (MSE) is 0.0171. By using a moving average to forecast the independent variables obtained the rate of inflation in the month of July 2014 is 0.514 , by using exponential smoothing to forecast the independent variables obtained by the rate of inflation in the month of July 2014 is 0.45, and by using seasonal method to forecast the independent variables obtained by the rate of inflation in the month of July 2014 is 0.93.
\end{abstract}

Keywords : Inflation, Neural Network Backpropagation, Mean Square Error

\begin{abstract}
ABSTRAK
Pada penelitian ini akan digunakan metode prediksi neural network dengan backpropagation, untuk memprediksi tingkat inflasi bulanan di indonesia. Dari hasil analisis data yang dilakukan disimpulkan bahwa Performa model neural network dengan backpropagation yang dibentuk dari data training dan divalidasi pada data testing memberikan tingkat akurasi prediksi yang cukup baik dengan nilai mean square error (MSE) 0,0171. Dengan menggunakan moving average untuk prediksi variabel input diperoleh tingkat inflasi di bulan juli 2014 sebesar 0,514, dengan menggunakan smoothing eksponensial untuk prediksi variabel input diperoleh tinkat inflasi di bulan juli 2014 sebesar 0,45, dan dengan menggunakan metode seasonal untuk prediksi variabel input diperoleh tingkat inflasi sebesar 0,93 .
\end{abstract}

Kata kunci: Inflasi, neural network backpropagation, rata-rata error kuadrat.

\section{PENDAHULUAN}

Inflasi adalah kenaikan harga barang dan jasa secara umum dimana barang dan jasa tersebut merupakan kebutuhan pokok masyarakat atau turunnya daya jual mata uang suatu negara (Badan Pusat Statistik, 2014). Secara sederhana inflasi diartikan sebagai meningkatnya harga-harga secara umum dan terus menerus. Kenaikan harga dari satu atau dua barang saja tidak dapat disebut inflasi kecuali bila kenaikan itu meluas (atau mengakibatkan kenaikan harga) pada barang lainnya. Kebalikan dari inflasi disebut deflasi (Bank Indonesia, 2014).

Kestabilan inflasi merupakan prasyarat bagi pertumbuhan ekonomi yang berkesinambungan yang pada akhirnya memberikan manfaat bagi peningkatan kesejahteraan masyarakat. Pentingnya pengendalian inflasi didasarkan pada pertimbangan bahwa inflasi yang tinggi dan tidak stabil memberikan dampak negatif kepada kondisi sosial ekonomi masyarakat. Bank Indonesia menjelaskan bahwa ada tiga dampak negatif dari tingginya nilai inflasi dan ketidakstabilan inflasi. Pertama, inflasi yang tinggi akan menyebabkan pendapatan riil masyarakat akan terus turun sehingga standar hidup dari masyarakat turun dan akhirnya menjadikan semua orang, terutama orang miskin, bertambah miskin. Kedua, inflasi yang tidak stabil akan menciptakan ketidakpastian (uncertainty) bagi pelaku ekonomi dalam mengambil keputusan. 
Pengalaman empiris menunjukkan bahwa inflasi yang tidak stabil akan menyulitkan keputusan masyarakat dalam melakukan konsumsi, investasi, dan produksi, yang pada akhirnya akan menurunkan pertumbuhan ekonomi. Ketiga, tingkat inflasi domestik yang lebih tinggi dibanding dengan tingkat inflasi di negara tetangga menjadikan tingkat bunga domestik riil menjadi tidak kompetitif sehingga dapat memberikan tekanan pada nilai rupiah (Bank Indonesia, 2014).

Penelitian mengenai peramalan inflasi di suatu negara mendapatkan perhatian yang positif bagi peneliti makroekonomi. Sebagian besar bank sentral menggunakan inflasi sebagai salah satu pertimbangan untuk mengambil kebijakan moneter. Kebijakan moneter diambil dengan pertimbangan nilai inflasi yang akan datang. Nilai inflasi sekarang, merupakan hasil dari kebijakan yang lalu, mungkin hanya memberikan informasi yang samar-samar. Bagi pemerintah, peramalan inflasi merupakan jembatan penghubung untuk mengetahui nilai inflasi yang akan datang. Penelitian ini merupakan pengembangan peramalan inflasi di Indonesia yang dapat memberikan input bagi Bank Indonesia sebagai pertimbangan pengambilan kebijakan.

Pada penelitian ini akan digunakan metode prediksi neural network dengan backpropagation, untuk memprediksi tingkat inflasi bulanan di masa yang akan datang. Data yang penulis gunakan adalah data tingkat inflasi bulanan di indonesia yang dikeluarkan oleh Badan Pusat Statistik dan Bank Indonesia.

Kelebihan metode neural network diantaranya melakukan generalisasi dan ekstraksi dari pola data tertentu, mampu mengakuisisi pengetahuan walau tidak ada kepastian, menyelesaikan masalah yang tidak terstruktur dan sulit didefinisikan, dan mampu melakukan perhitungan secara paralel sehingga proses lebih singkat.

\section{BAHAN DAN METODE}

\section{Data Mining}

Data mining adalah rangkaian proses untuk menggali nilai tambah berupa informasi yang belum terekplorasi dari sebuah basis data, melakukan ekplorasi dengan cara-cara tertentu untuk memanipulasi data menjadi informasi yang lebih berharga dengan cara mengektraksi dan mengenali pola penting dari basis data (Han \& Kamber, 2006). Menurut Daryl
Pregibons dalam (Gorunescu, 2011) "Data mining adalah perpaduan dari ilmu statistik, kecerdasan buatan, dan penelitian bidang database". Nama data mining berasal dari kemiripan antara pencarian informasi yang bernilai dari database yang besar dengan menambang sebuah gunung untuk sesuatu yang bernilai (Sumathi, 2006). Keduanya memerlukan penyaringan melalui sejumlah besar material, atau menyelidiki dengan cerdas untuk mencari keberadaan sesuatu yang disebut bernilai tadi.

Data Mining merupakan teknologi baru yang sangat berguna untuk membantu perusahaan-perusahaan menemukan informasi yang sangat penting dari gudang data mereka. Beberapa aplikasi data mining fokus pada prediksi, mereka meramalkan apa yang akan terjadi dalam situasi baru dari data yang menggambarkan apa yang terjadi di masa lalu (Witten, Frank, \& Hall, 2011).

\section{Neural Network}

Neural network atau jaringan syaraf tiruan adalah merupakan salah satu representasi buatan dan otak manusia yang selalu mencoba mensimulasikan proses pembelajaran pada otak manusia. Istilah buatan disini digunakan karena jaringan syaraf ini diimplementasikan dengan menggunakan program komputer yang mampu menyelesaikan sejumlah proses perhitungan selama proses pembelajaran (Kusuma Dewi, 2003). Neural network adalah (Han, 2006) satu set unit input/output yang terhubung dimana tiap relasinya memiliki bobot. Hal yang perlu mendapat perhatian istimewa adalah bahwa jaringan syaraf tiruan tidak diprogram untuk menghasilkan keluaran tertentu. Semua keluaran atau kesimpulan yang ditarik oleh jaringan didasarkan pada pengalamanya selama mengikuti proses pembelajaran. Pada proses pembelajaran, kedalam jaringan syaraf tiruan dimasukkan pola-pola input (dan output) lalu jaringan akan diajari untuk memberikan jawaban yang bisa diterima (Diyah Puspitaningrum, 2006).

Neural Network dimaksudkan untuk mensimulasikan perilaku sistem biologi susunan syaraf manusia, yang terdiri dari sejumlah besar unit pemroses yang disebut neuron, yang beroperasi secara paralel (Alpaydin, 2010). Neuron mempunyai relasi dengan synapse yang mengelilingi neuronneuron lainnya. Susunan syaraf tersebut dipresentasikan dalam neural network berupa graf yang terdiri dari simpul (neuron) yang dihubungkan dengan busur, yang 
berkorespondensi dengan synapse. Sejak tahun 1950-an, neural network telah digunakan untuk tujuan prediksi, bukan hanya klasifikasi tapi juga untuk regresi dengan atribut target kontinu (Vecellis, 2009).

Neural network terdiri dari dua lapisan atau lebih, meskipun sebagian besar jaringan terdiri dari tiga lapisan : lapisan input, lapisan tersembunyi, dan lapisan output (Larose, 2005). Pendekatan neural network dimotivasi oleh jaringan saraf biologis. Secara kasar, neural network adalah satu set terhubung input/output unit, di mana masing-masing sambungan memiliki berat yang terkait dengannya. Neural network memiliki beberapa ciri yang membuat mereka populer untuk clustering. Pertama, neural network adalah arsitektur pengolahan inheren paralel dan terdistribusi. Kedua, neural network belajar dengan menyesuaikan bobot interkoneksi dengan data, Hal ini memungkinkan neural network untuk "menormalkan" pola dan bertindak sebagai fitur (atribut) extractors untuk kelompok yang berbeda. Ketiga, neural network memproses vektor numerik dan membutuhkan pola objek untuk diwakili oleh fitur kuantitatif saja (Gorunescu, 2011).

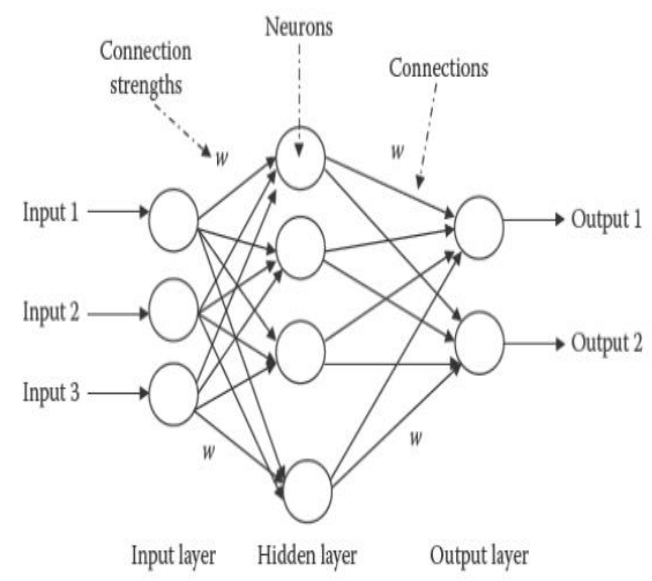

Sumber: Shukla et al. (2010)

Gambar 1: Arsitektur Neural Network

\section{Algoritma Neural Network \\ Backpropagation}

Algoritma pelatihan backpropagation atau ada yang menterjemahkan menjadi propagasi balik pertama kali dirumuskan oleh Paul Werbos pada tahun 1974 dan dipopulerkan oleh Rumelhart bersama McClelland untuk dipakai pada neural network. Metode backpropagation pada awalnya dirancang untuk neural network feedforward, tetapi pada perkembangannya, metode ini diadaptasi untuk pembelajaran pada model neural network lainnya (Astuti, 2009).

Backpropagation merupakan salah satu algoritma pembelajaran dalam jaringan syaraf tiruan. Proses pembelajaran dalam backpropagation dilakukan dengan penyesuaian bobot-bobot jaringan syaraf tiruan dengan arah mundur berdasarkan nilai error dalam proses pembelajaran (Kusrini, 2009). Penemuan algoritma backpropagation untuk multilayer perceptron(MLP), merupakan metode yang sistematis untuk training sehingga bisa dilakukan dan lebih efisien. Algoritma backpropagation berasal dari learning rule Widrow dan Hoff, disusun oleh Werbos (1974), dibuat oleh Parker (1985), Rumelhart Hinton, Williams (Rumelhart dan Williams, 1986) dan peneliti lainnya (Maimon, 2005).

Algoritma pelatihan backpropagation terdiri dari dua tahapan yaitu feedforward dan backpropagation dari galatnya. Langkah pembelajaran dalam algoritma backpropagation adalah sebagai berikut (Kusumadewi, 2010):

- Inisialisasi bobot (ambil bobot awal dengan nilai random yang cukup kecil).

- Kerjakan langkah-langkah berikut selama kondisi berhenti bernilai FALSE:

1. Untuk tiap-tiap pasangan elemen yang akan dilakukan pembelaajaran, kerjakan:

Feedforward:

a. Tiap-tiap unit input $(\mathrm{Xi}, \mathrm{i}=1,2,3, \ldots, \mathrm{n})$ menerima sinyal $x_{i}$ dan meneruskan sinyal tersebut ke semua unit pada lapisan yang ada di atasnya (lapisan tersembunyi).

b. Tiap-tiap unit tersembunyi $(\mathrm{Zj}, \mathrm{j}=1,2,3, \ldots, \mathrm{p})$ menjumlahkan sinyalsinyal input terbobot:

$$
\mathrm{z}_{-} \mathrm{in}_{\mathrm{j}}=\mathrm{v} 0_{\mathrm{j}}+\sum \mathrm{x}_{\mathrm{i}} \mathrm{vi}
$$

Gunakan fungsi aktivitas untuk menghitung sinyal outputnya:

$$
\mathrm{z}_{\mathrm{j}}=\mathrm{f}\left(\mathrm{z}_{-} \mathrm{in}_{\mathrm{j}}\right)
$$

Kirimkan sinyal tersebut ke semua unit dilapisan atasanya (unit-unit output)

c. Tiap-tiap unit output $\left(\mathrm{Y}_{\mathrm{k}}, \mathrm{k}=1,2, \ldots \ldots\right.$, $\mathrm{m})$ menjumlah sinyal-sinyal input terbobot

$$
\mathrm{y}_{-} \mathrm{in}_{\mathrm{k}}=\mathrm{wo}_{\mathrm{k}}+\sum \mathrm{z}_{\mathrm{j}} \mathrm{w}_{\mathrm{jk}}
$$

Gunakan fungsi aktivitas untuk menghitung sinyal output:

$$
\mathrm{y}_{\mathrm{k}}=\mathrm{f}\left(\mathrm{y} \_ \text {in } \mathrm{k}\right)
$$


Dan kirimkan sinyal tersebut ke semua unit dilapisan atasnya (unit-unit output).

\section{Backpropagation}

d. Tiap-tiap unit output $(\mathrm{Yk}, \mathrm{k}=1,2, \ldots \ldots$, m) menerima target pola yang berhubungan dengan pola input pembelajaran, hitung informasi errornya:

$$
\delta_{\mathrm{k}}=\left(\mathrm{t}_{\mathrm{k}}-\mathrm{y}_{\mathrm{k}}\right) \mathrm{f}^{\prime}\left(\mathrm{y}-\mathrm{in}_{\mathrm{k}}\right)
$$

Kemudian hitung koreksi bobot (yang nanti akan digunakan untuk memperbaiki nilai $\mathrm{w}_{\mathrm{jk}}$ ):

$$
\Delta \mathrm{w}_{\mathrm{jk}}=\alpha \delta_{\mathrm{k}} \mathrm{Z}_{\mathrm{j}}
$$

Hitung juga koreksi bias (yang nantinya akan digunakan untuk memperbaiki nilai $\left.\mathrm{w}_{0 \mathrm{k}}\right)$ :

Kirimkan $\delta_{\mathrm{k}}$ ini ke unit-unit yang ada dilapisan bawahnya.

e. Tiap-tiap unit tersembunyi $(\mathrm{Zj}, \mathrm{j}=1,2,3, \ldots, \mathrm{p})$ menjumlahkan delta inputnya (dari unit-unit yang berada pada lapisan di atasanya):

$$
\delta \text { in }_{\mathrm{j}}=\delta_{\mathrm{k}} \mathrm{W}_{\mathrm{ij}}
$$

Kalikan nilai ini dengan turunan dari fungsi aktivasi untuk menghitung informasi error:

$$
\delta \delta_{j}=\delta \text { in }_{j} \mathrm{f}^{\prime}\left(\mathrm{z} \_\mathrm{in}_{\mathrm{j}}\right)
$$

Kemudian hitung koreksi bobot untuk memperbaiki nilai $\mathrm{v}_{\mathrm{ij}}$ :

$$
\Delta \mathrm{v}_{\mathrm{ij}}=\alpha \delta_{\mathrm{j}} \mathrm{x}_{\mathrm{i}}
$$

Hitung juga koreksi bias untuk memperbaiki nilai $\mathrm{v}_{0 \mathrm{j}}$ :

$$
\Delta \mathrm{v}_{0 \mathrm{j}}=\alpha \delta \mathrm{j}
$$

f. Tiap-tiap unit output $\left(\mathrm{Y}_{\mathrm{k}}, \mathrm{k}=1,2, . . \mathrm{m}\right)$ memperbaiki bias dan bobotnya $(\mathrm{j}=$ $0,1,2, \ldots \mathrm{p})$

$$
\underset{\Delta \mathrm{w}_{\mathrm{jk}}}{\mathrm{w}_{\mathrm{k}}}(\text { baru })=\mathrm{w}_{\mathrm{jk}}(\text { lama })+
$$

Tiap-tiap unit tersembunyi $(\mathrm{Zj}, \mathrm{j}=$ $1,2, \ldots$, p) memperbaki bias dan bobotnya $(i=0,1,2, \ldots n)$.

$$
\mathrm{v}_{\mathrm{ij}}(\mathrm{baru})=\mathrm{v}_{\mathrm{ij}}(\text { lama })+\Delta \mathrm{v}_{\mathrm{ij}}
$$

\section{Tes kondisi berhenti}

\section{Metode Pengumpulan Data}

\section{a. Data Primer}

Data primer adalah data yang dikumpulkan langsung oleh peneliti dari responden, dan bukan berasal dari pengumpulan data yang pernah dilakukan sebelumnya. Data primer adalah data yang diperoleh dari sumber-sumber asli. Sumber asli disini diartikan sebagai sumber pertama darimana data tersebut diperoleh.

\section{b. Data Sekunder}

Data sekunder adalah data yang telah diolah dari data primer. Contoh: data kependudukan yang dikeluarkan oleh Badan Pusat Statistik (BPS). Pada penelitian ini penulis menggunakan data sekunder, yaitu data inflasi bulanan indonesia menurut kelompok pengeluaran tahun 2006 - 2014 yang dikeluarkan oleh BPS lewat website resminya (www.bps.go.id, 2014). Jenis data sekunder yang lain pada penelitian ini adalah semua pustaka dan laporan penelitian yang telah dilakukan baik dalam bentuk jurnal maupun kumpulan seminar nasional yang berhubungan dengan peramalan tingkat inflasi.

\section{Tahap Penelitian}

Terdapat beberapa tahap dalam pengolahan data eksperimen, pada penelitian ini menggunakan model Cross-Standard Industry for Data Mining (CRISP-DM), yaitu seperti terlihat pada diagram di bawah ini: (Sumathi, 2006)

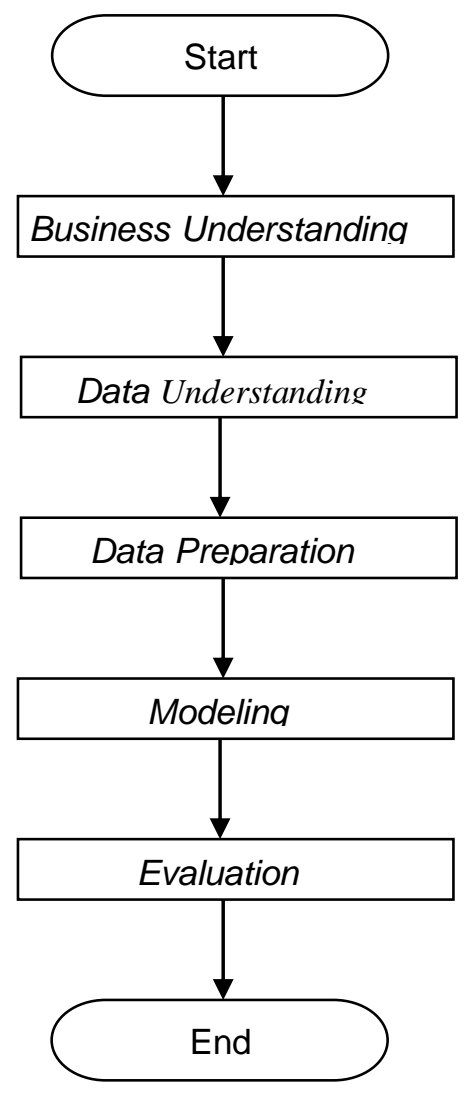

Sumber: Sumathi (2006)

Gambar 2. Diagram Tahap Penelitian 


\section{HASIL DAN PEMBAHASAN}

\section{Hasil Penelitian}

Data yang diperoleh untuk penelitian ini sebanyak 102 record, dimana $80 \%$ dari data tersebut sebagai data training, dan $20 \%$ dari data sebagai data testing. Variabel input pada penelitian ini terdiri dari tujuh variabel, yaitu: 1. Inflasi Makanan, 2. Inflasi Makanan Jadi, Minuman, Rokok, dan Tembakau, 3. Inflasi Perumahan, Air, Listrrik, Gas, dan Bahan Bakar, 4. Inflasi Sandang, 5. Inflasi Kesehatan, 6. Inflasi Pendidikan, Rekreasi, dan Olahraga, 7. Inflasi Transpor, Komunikasi, dan Jasa Keuangan, Sedangkan variabel output adalah variabel Inflasi Umum. Perangkat lunak yang digunakan untuk menganalisa adalah mathlab versi 7.7 .

Proses pelatihan jaringan syaraf tiruan menggunakan $80 \%$ dari total data, pada proses ini akan dilakukan pelatihan dengan arsitektur neural network yang berbeda-beda. Setiap arsitektur neural network akan menghasilkan bobot pelatihan yang terakhir yang akan digunakan sebagai bobot awal saat melakukan pengujian.

Hasil pelatihan oleh mathlab versi 7.7 untuk arsitektur jaringan 7-2-1 diperlihatkan oleh gambar di bawah ini:

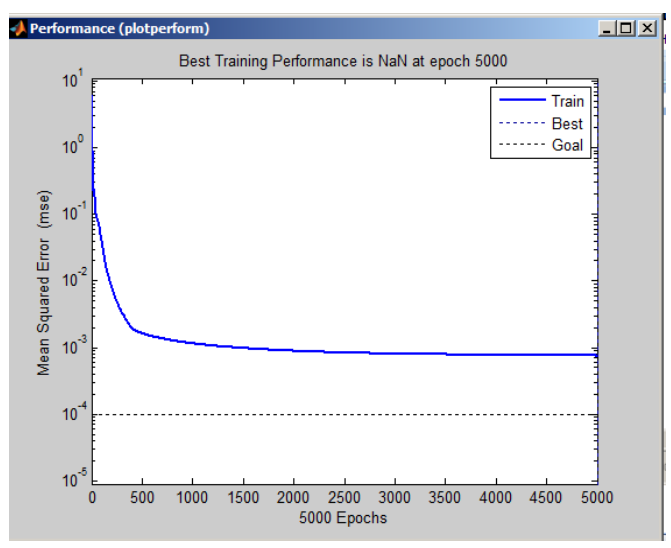

Sumber: Hasil Percobaan Menggunakan Mathlab 7.7

Gambar 3. Mean Sequare Error dengan arsitektur Jaringan 7-2-1
Mencari network terbaik dilakukan dengan cara mengubah jumlah neuron/node pada lapisan tersembunyi secara trial and error, maka di dapatkan konfigurasi terbaik. Berikut tabel Mean Square Error(MSE) dari beberapa variasi jaringan yang dilatih menggunakan mathlab versi 7.7 pada data training dengan maximal epoch(iterasi) = 5000 , learning rate $(\alpha)=1$, momentum $=0.8$, dan target error $=0.0001$ :

Tabel 1. Hasil Pelatihan Arsitektur Jaringan

\begin{tabular}{cc}
\hline Arsitektur Jaringan & MSE \\
\hline $7-2-1$ & 0,000752 \\
\hline $\mathbf{7 - 5 - 1}$ & $\mathbf{0 , 0 0 0 5 2 9}$ \\
\hline $7-10-1$ & 0,000747 \\
\hline $7-15-1$ & 0,000653 \\
\hline $7-20-1$ & 0,001070 \\
\hline $7-25-1$ & 0,216000 \\
\hline $7-30-1$ & 0,217000 \\
\hline
\end{tabular}

Sumber: Hasil Percobaan Menggunakan Mathlab 7.7

Berdasarkan tabel di atas, maka didapatkan konfigurasi jaringan terbaik sebagai berikut:

1. Jumlah neuron lapisan input $=7$

2. Jumlah neoron lapisan tersembunyi $=5$

3. Jumlah neuron lapisan output $=1$

Dengan nilai MSE sebesar 0,000529.

Arsitektur jaringan terbaik yang didapat saat pelatihan di atas akan digunakan sebagai arsitektur jaringan untuk mencari prediksi tingkat inflasi pada data testing. Bobot awal pada data testing adalah bobot terakhir saat pelatihan dari arsitektur jaringan terbaik.

Hasil peramalan inflasi di Indosesia dengan metode Neural Network Backpropagation menggunakan mathlab versi 7.7 pada data testing diperlihatkan pada tabel di bawah ini:

Tabel 2. Prediksi Inflasi Bulanan Indonesia dengan NN Backpropagation 
Langkah selanjutnya adalah memprediksi inflasi bulan depan dengan menggunakan model jaringan terbaik dari metode neural network backpropagation. Berhubung data inflasi bersifat time series, maka dalam pembahasan ini akan digunakan tiga metode prediksi time series, yaitu metode moving average, smoothing eksponensial, dan metode seasonal untuk memprediksi variabel input. Berikut adalah tabel hasil prediksi inflasi umum bulanan berdasarkarkan ketiga variabel input diatas pada bulan juli 2014:

Tabel 3. Prediksi Inflasi berdasarkan metode time series bulan juli 2014

\begin{tabular}{cc}
\hline Metode & Prediksi \\
\hline Moving Average & 0,514 \\
\hline Smoothing Eksponensial & 0,45 \\
\hline Seasonal & 0,97
\end{tabular}

\section{Evaluasi dan Validasi}

a. Performa Model

untuk mengukur ketepatan dan keakuratan model prediksi inflasi bulanan di Indonesia ditentukan dengan menghitung nilai Mean Square Error (MSE), Root Mean Square Error (RMSE), dan Mean Absolute Deviation (MAD). Diperoleh nilai Mean Absolute Deviation (MAD) sebesar 0,0781, nilai Mean Square Error (MSE) sebesar 0,0171, dan nilai Root Mean Square Error (RMSE) adalah sebesar 0,1306.

\section{b. Grafik Performa Model}

Untuk grafik performa model jaringan neural network struktur backpropagation data testing diperlihatkan oleh gambar di bawah ini:

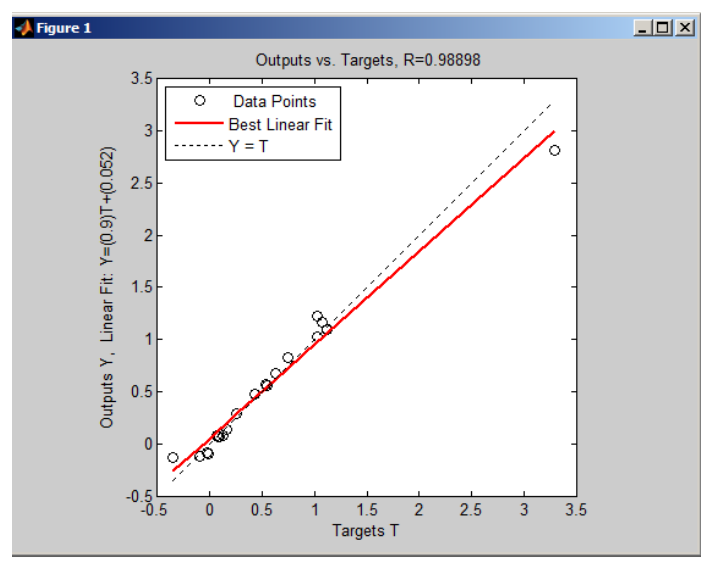

Sumber: Hasil Pengujian Menggunakan Mathlab 7.7

\section{Gambar 4. Perbandingan Antara Target} dengan Output Data Testing

c. Ferforma Model Berdasarkan Metode Time Series

\begin{tabular}{|c|c|c|c|c|}
\hline Tah & un/Bulan & Real & Prediksi & $\begin{array}{r}\text { error }=\mathbf{T}- \\
\mathbf{Y}\end{array}$ \\
\hline 2014 & Juni & 0,4300 & 0,4806 & $-0,0506$ \\
\hline & Mei & 0,1600 & 0,1377 & 0,0223 \\
\hline & & $\begin{array}{l}- \\
-\end{array}$ & & \\
\hline & April & 0 & $-0,0998$ & 0,0798 \\
\hline & & 2 & & \\
\hline & & 0 & & \\
\hline & & 0 & & \\
\hline & Maret & 0,0800 & 0,0675 & 0,0125 \\
\hline & Februari & 0,2600 & 0,2908 & $-0,0308$ \\
\hline & Januari & 1,0700 & 1,1636 & $-0,0936$ \\
\hline 2013 & Desember & 0,5500 & 0,5586 & $-0,0086$ \\
\hline & November & 0,1200 & 0,0788 & 0,0412 \\
\hline & Oktober & 0,0900 & 0,0700 & 0,0200 \\
\hline & September & - & & \\
\hline & & 0 & & \\
\hline & & 3 & $-0,1348$ & $-0,2152$ \\
\hline & & 5 & & \\
\hline & & 0 & & \\
\hline & & 0 & & \\
\hline & Agustus & 1,1200 & 1,0914 & 0,0286 \\
\hline & Juli & 3,2900 & 2,8203 & 0,4697 \\
\hline & Juni & 1,0300 & 1,2207 & $-0,1907$ \\
\hline & Mei & - & & \\
\hline & & 0 & & \\
\hline & & ' & $-0,0797$ & 0,0497 \\
\hline & & 3 & & \\
\hline & & 0 & & \\
\hline & & 0 & & \\
\hline & April & - & & \\
\hline & & 0 & & \\
\hline & & 1 & $-0,1237$ & 0,0237 \\
\hline & & 0 & & \\
\hline & & 0 & & \\
\hline & & 0 & & \\
\hline & Maret & 0,6300 & 0,6699 & $-0,0399$ \\
\hline & Februari & 0,7500 & 0,8243 & $-0,0743$ \\
\hline & Januari & 1,0300 & 1,0269 & 0,0031 \\
\hline 2012 & Desember & 0,5400 & 0,5754 & $-0,0354$ \\
\hline & November & 0,0700 & 0,0742 & $-0,0042$ \\
\hline & Oktober & 0,1600 & 0,0136 & 0,1464 \\
\hline
\end{tabular}


Untuk performa model berdasarkan ketiga metode time series di atas ditunjukkan oleh tabel berikut:

Tabel 4. Performa Model dengan Input Metode Time Series

\begin{tabular}{cc}
\hline Metode & MSE \\
\hline Moving Average & 0,11 \\
\hline Smoothing Eksponensial & 0,39 \\
\hline Seasonal & 0,09 \\
\hline
\end{tabular}

\section{KESIMPULAN}

Berdasarkan analisis data yang telah dilakukan dapat disimpulkan bahwa:

1. Performa model neural network dengan backpropagation yang dibentuk dari data training dan divalidasi pada data testing memberikan tingkat akurasi prediksi yang cukup baik dengan nilai mean square error (MSE) 0,0171.

2. Penggunaan moving average untuk memprediksi variabel input kemudian variabel input tersebut dimasukkan ke dalam model neural network dengan backpropagation memberikan nilai MSE sebesar 0,11 dengan nilai inflasi umum pada bulan juli 2014 sebesar 0,514.

3. Penggunaan smoothing eksponensial untuk memprediksi variabel input kemudian variabel input tersebut dimasukkan ke dalam model neural network dengan backpropagation memberikan nilai MSE sebesar 0,39 dengan nilai inflasi umum pada bulan juli 2014 sebesar 0,45 .

4. Penggunaan metode seasonal untuk memprediksi variabel input kemudian variabel input tersebut dimasukkan ke dalam model neural network dengan backpropagation memberikan nilai MSE sebesar 0,09 dengan nilai inflasi umum pada bulan juli 2014 sebesar 0,97. Nilai ini hampir persis sama dengan nilai inflasi yang dikeluarkan oleh Badan Pusat Statistik yaitu sebesar 0,93 .

5. Penggunaan neural network dengan backpropagation berdasarkan metode seasonal lebih baik dibandingkan dengan moving average dan smoothing eksponensial.

6. Faktor suhu politik, kondisi ekonomi yang tidak stabil, kebijakan pemerintah yang tiba-tiba seperti menaikkan BBM, hari lebaran yang bulannya selalu bergeser setiap tahun, pola konsumsi masyarakat, dan lain sebagainya bisa menyebabkan perubahan laju inflasi yang ekstrim sehingga sangat sulit untuk diprediksi.

\section{DAFTAR PUSTAKA}

[1] Alpaydin, Ethem. (2010). Introduction to Machine Learning. London: The MIT Press.

[2] Badan Pusat Statistik (BPS). 2014. Inflasi, <http://www.bps.go.id /aboutus.php?id_subyek=03\&tabel=1\&f l=2> Diunduh pada tanggal 03 Agustus 2014.

[3] Gorunescu, Florin (2011). Data Mining: Concepts, Models, and Techniques. Verlag Berlin Heidelberg: Springer

[4] Han, J.,\&Kamber, M. (2006).Data Mining Concept and Tehniques.San Fransisco: Morgan Kauffman.

[5] Kusrini,\&Luthfi, E. T. (2009).Algoritma Data Mining. Yogyakarta: Andi Publishing.

[6] Kusumadewi, Sri (2010). Pengantar Jaringan Syaraf Tiruan. Yogyakarta.Teknik Informatika FT UII.

[7] Larose, D. T. (2005).Discovering Knowledge in Data. New Jersey: John Willey \& Sons, Inc.

[8] Maimon, Oded\&Rokach, Lior.(2005). Data Mining and Knowledge Discovey Handbook. New York: Springer

[9] Myatt, Glenn J. (2007). Making Sense of Data: A Practical Guide to Exploratory Data Analysis and Data Mining. New Jersey: John Wiley \& Sons, Inc.

[10] Purnomo, M. H., \& Kurniawan, A. (2006). Supervised Neural Network dan Aplikasinya. Yogyakarta: Graha Ilmu.

[11] Puspitaningrum, Diyah (2006). Pengantar Jaringan Syaraf Tiruan. Yogyakarta: Andi Offset.

[12] Santoso, Budi. (2007). Data Mining Teknik Pemanfaatan Data untuk Keperluan Bisnis. Yogyakarta: Graha Ilmu.

[13] Shukla, A., Tiwari, R., \& Kala, R. (2010). Real Life Applications of Soft Computing. United States of America on: Taylor and Francis Group, LLC.

[14] Sogala, Satchidananda S. (2006). Comparing the Efficacy of the Decision Trees with Logistic Regression for Credit Risk Analysis. India.

[15] Sugiyono, (2009). Metode Penelitian Bisnis. Bandung: Alfabeta 
[16] Sumathi, \& S., Sivanandam, S.N. (2006). Introduction to Data Mining and its Applications. Berlin Heidelberg New York: Springer

[17] Vercellis, Carlo (2009). Business Intelligent: Data Mining and Optimization for Decision Making. Southern Gate, Chichester, West Sussex: John Willey \& Sons, Ltd.

[18] Witten, I. H., Frank, E., \& Hall, M. A. (2011).Data Mining: Practical Machine Learning and Tools. Burlington: Morgan Kaufmann Publisher.

[19] Wu, Xindong\& Kumar, Vipin. (2009). The Top Ten Algorithms in Data Mining. Boca Raton: CRC Press. 